\title{
A Rare Case of Chronic Recurrent Multifocal Osteomyelitis with Undifferentiated Juvenile Idiopathic Arthritis, Uveitis, and Psoriasis
}

\author{
Yongdong Zhao ${ }^{1 *}$, Shannon K. Foster ${ }^{2}$, Todd J. Murdock ${ }^{3}$, Margret Schlesinger ${ }^{1}$, \\ Carol A. Wallace ${ }^{1}$ \\ ${ }^{1}$ Pediatric Rheumatology, Seattle Children's Hospital, Seattle, WA, USA \\ ${ }^{2}$ Western Montana Clinic, Missoula, MT, USA \\ ${ }^{3}$ Rocky Mountain Eye Center, Missoula, MT, USA \\ Email: yongdong.zhao@seattlechildrens.org
}

Received 6 June 2016; accepted 11 July 2016; published 14 July 2016

Copyright (C) 2016 by authors and Scientific Research Publishing Inc.

This work is licensed under the Creative Commons Attribution International License (CC BY). http://creativecommons.org/licenses/by/4.0/

c) (i) Open Access

\section{Abstract}

We report here a 17-year-old boy with a complicated presentation of undifferentiated juvenile idiopathic arthritis, vision-threatening uveitis and chronic recurrent multifocal osteomyelitis (CRMO) in the pelvis. His severe iritis needed subtenon injections and only responded to infliximab after failing multiple biologics. Unfortunately he later developed infliximab-associated psoriasis. A combination of infliximab and ustekinumab induced remission of his arthritis, osteomyelitis, uveitis and psoriasis without experiencing severe infections.

\section{Keywords}

Juvenile Idiopathic Arthritis, Uveitis, Psoriasis, Chronic Recurrent Multifocal Osteomyelitis, Infliximab, Ustekinumab

\section{Introduction}

Chronic recurrent multifocal osteomyelitis is a rare condition [1] that may coexist with ankylosing spondylitis [2] [3], psoriasis [4] [5], and inflammatory bowel disease (IBD) [4] [6]. Patients usually present with persistent bone pain. It is a diagnosis of exclusion and $\mathrm{X}$ ray is usually the first imaging modality. However, $\mathrm{X}$ rays lack sensitivity compared to bone scan and whole-body MRI [7] [8]. Whole-body MRI [9] is the most sensitive modality to identify involved areas because symmetrical lesions commonly occur near growth plates that bone scan fails

*Corresponding author. 
to detect. Focal MRI is helpful to evaluate affected sites with more details when whole-body MRI is not available. When CRMO is suspected in appropriate clinical setting, it is important to obtain further imaging when affected sites are difficult to assess.

Acute anterior uveitis is most commonly seen in children with enthesitis-related arthritis [10]-[12] and presents with eye pain, redness and photophobia. Steroid eye drops are the first-line treatment. But often systemic medications such as methotrexate and/or monoclonal anti-TNF agents are necessary to induce inactive disease and preserve vision [13]-[16].

Despite their therapeutic effectiveness, anti-TNF agents may cause worsening or new onset of psoriasis in adults and children. The mechanism is not well defined, but this has been seen in patients taking anti-TNF agents for a variety of conditions including inflammatory bowel disease, rheumatoid arthritis, and ankylosing spondylitis [17]-[21]. The current recommendation when psoriasis develops is to discontinue or switch to another anti-TNF agent when the affected skin area is greater than $5 \%$ of total body or palmar plantar psoriasis has developed [21]. For patients with refractory uveitis, monoclonal anti-TNF agents are reported to have the best efficacy [13]-[16]. When patients have complications with anti-TNF associated psoriasis, it poses a practical challenge to their care.

\section{Case Background}

In 2009, at age 10 years 11 months, a Caucasian male presented with pain and swelling in his fingers, knees, ankles, toes, and pain in his hips, mid back and temporomandibular joints (TMJs) accompanied by greater than 2 hours of morning stiffness. He also had a thickened crusty rash on his scalp which was consistent with seborrheic dermatitis. He was treated with prednisone by his primary pediatrician; with taper to $5 \mathrm{mg}$ daily, his symptoms recurred. He was seen by pediatric rheumatology in August 2009 and was taking prednisone $10 \mathrm{mg}$ daily, iron $325 \mathrm{mg}$ daily, ibuprofen $400 \mathrm{mg}$ twice daily. At birth, he had apnea but went home on the same day as his mother. At age of 2, he had intoeing and was diagnosed with anterior tibial torsion. At age of 4 , he had a mildly displaced distal tibial and fibular fracture due to injury, which healed after casting. His review of systems was positive for headaches, joint swelling, joint pain, poor sleep, weight loss, and the scalp rash. His family history was positive for asthma (his brother), rheumatoid arthritis (cousin) and polyarteritis nodosa and renal transplant (cousin). On his physical exam, his weight was $46.7 \mathrm{~kg}\left(90.7^{\text {th }}\right.$ percentile) and height was $1.40 \mathrm{~m}\left(32.3^{\text {th }}\right.$ percentile) with normal temperature, blood pressure and pulse. His exam was notable for swelling, tenderness and warmth in right $2^{\text {nd }}$ to $4^{\text {th }}$ metacarpophalangeal joints (MCPs), right $1^{\text {st }}$ to $4^{\text {th }}$ distal interphalangeal joints (DIPs), left $1^{\text {st }}, 2^{\text {nd }}, 3^{\text {rd }}$, and $5^{\text {th }}$ DIPs and left $2^{\text {nd }}, 3^{\text {rd }}, 5^{\text {th }}$ MCPs, knees, ankles, and subtalar joints and decreased mouth opening $(2.5 \mathrm{~cm})$ without deviation. He was unable to make a fist or do a squat. He had tenderness over the greater trochanter areas bilaterally. There was no leg length discrepancy. Modified Schober test was $21 \mathrm{~cm}$. His skin was clear except a very thick crusting patch on his scalp. He did not have nail pitting or dactylitis. His initial laboratory testing revealed normal white blood cells (WBC), hemoglobin, hematocrit, platelet, alanine aminotransferase (ALT), aspartate aminotransferase (AST), blood urea nitrogen (BUN), creatinine, c reactive protein (CRP) $8.73 \mathrm{mg} / \mathrm{dL}$ (normal < 0.28), erythrocyte sedimentation rate (ESR) $45 \mathrm{~mm} / \mathrm{hr}$ (normal < 10), negative urine analysis, positive p-ANCA, negative PR3 and MPO, rheumatoid factor, anti-cyclic citrullinated peptide antibody (anti-CCP), and positive HLA-B27 with antinuclear antibody (ANA) 1:320. Bilateral knee and ankle X rays showed mild osteopenia without signs of erosion or joint space narrowing. No MRI was obtained at diagnosis because there was no concern of chronic osteomyelitis at that time.

\section{Clinical Course}

Detailed course was illustrated in Figure 1. He was diagnosed with undifferentiated juvenile idiopathic arthritis based on duration of arthritis longer than 6 weeks, the age of onset of arthritis in a male $>6$ years, positivity of HLA-B27, possible psoriasiform scalp rash and acute anterior uveitis based on International League of Associations for Rheumatology (ILAR) criteria [22]. He was treated with subcutaneous methotrexate at $25 \mathrm{mg}$ per week and prednisone at his first visit. Fluocinonide was prescribed for his scalp rash. His scalp rash resolved at his return visit in November 2009. Multiple joint injections were performed due to persistent arthritis until etanercept was started at $50 \mathrm{mg}$ weekly in September 2010. Heself discontinued methotrexate two months later.

In April 2011, he developed florid uveitis in his right eye that was treated with prednisolone eye drops. On his eye exam in June 2011, he still had 1 - 2+ injection, 3 - 4+ cells in anterior chamber, posterior synechiae, 1+ cell 


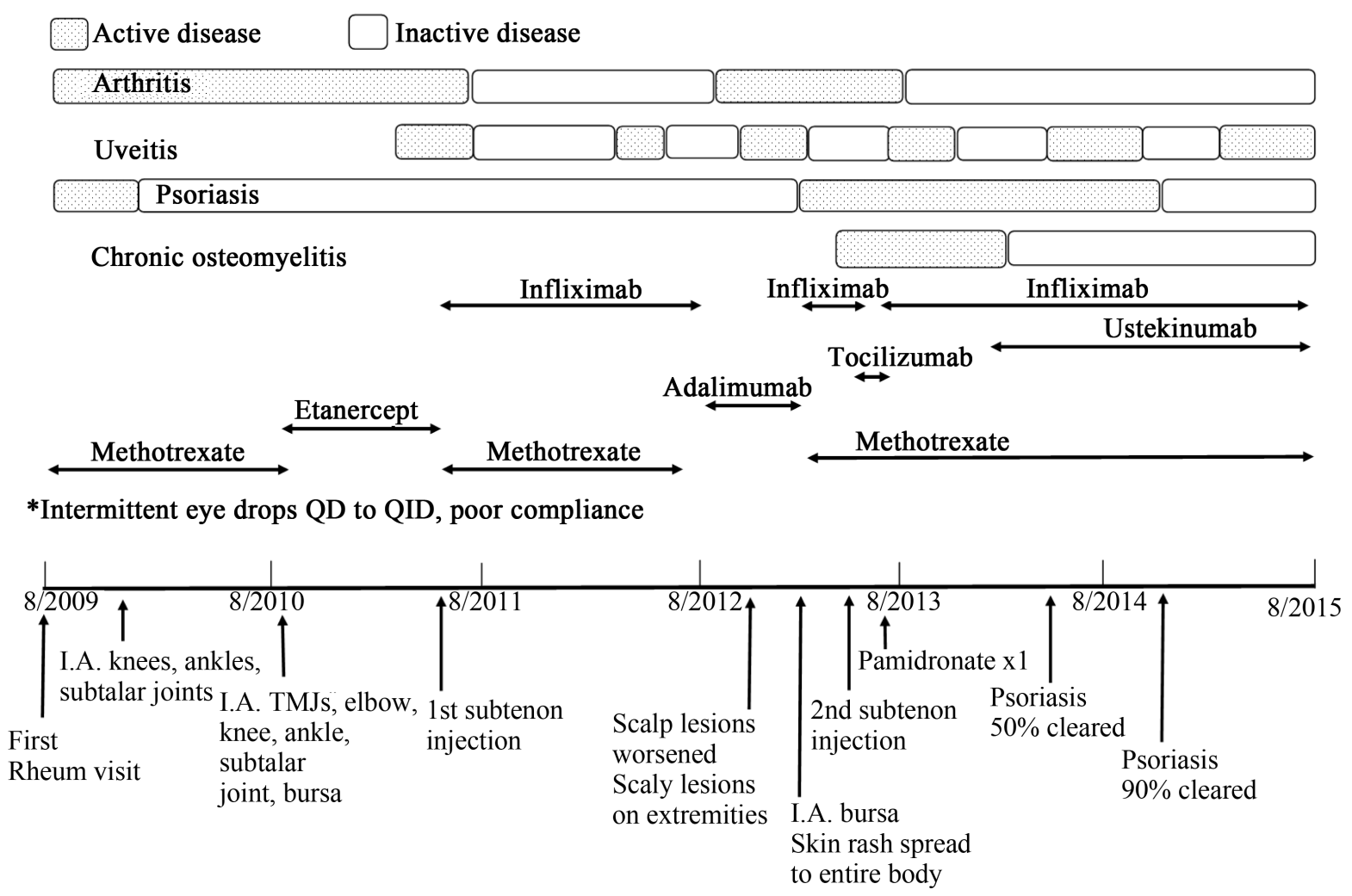

Figure 1. Clinical course including the onset and progress of arthritis, uveitis, psoriasis, and chronic osteomyelitis is shown. Major procedures including intraarticular corticosteroid injections and subtenon injection as well as systemic medications usage are listed.

in vitreous of his right eye. Because of persistent active uveitis, he received his first subtenon injection to the right eye at the end of June 2011. In addition, his left knee and TMJs were injected on the same day for active arthritis. Infliximab $5 \mathrm{mg} / \mathrm{kg}$ (300 mg) along with low dose methotrexate ( $7.5 \mathrm{mg}$ po weekly) were initiated in July 2011 to better control his uveitis.

His uveitis responded to this treatment regimen within a month. Infliximab dose was increased from $5 \mathrm{mg} / \mathrm{kg}$ (300 mg) to $6 \mathrm{mg} / \mathrm{kg}$ (400 mg) after a uveitis flare. Due to poor intravenous access, infliximab was switched to adalimumab 40 mg every other week in September 2012. His uveitis became active in November 2012 and continued to worsen despite using difluprednate eye drops 2 - 6 times a day. Switching back to infliximab with a surgical port quickly resolved his uveitis.

In November 2012, he developed skin lesions diagnosed as psoriasis on his scalp, behind the right ear and on the left upper arm. In February 2013, his left greater trochanter bursa was injected with glucocorticoid. The psoriasis spread to his entire body with diffuse lesions on his trunk, arms and legs and hyperkeratotic fissured plaques on his palms and soles (Figure 2). Topical treatments including ketoconazole $2 \%$ shampoo, tar and salicylic acid shampoos, fluocinonide $0.05 \%$ scalp oil for the scalp and topical clobetasol $0.05 \%$ ointment, calcipotriene $0.005 \%$ cream or protopic $0.1 \%$ ointment for the body were not successfully though he was not compliant consistently. Oral cyclosporin at $4 \mathrm{mg} / \mathrm{kg}$ was started. His diffuse body rash cleared, but the scalp, palm and sole plaques persisted. Cyclosporine was eventually discontinued due to hypertension.

In March 2013, MRI of pelvis with and without contrast was performed due to persistent hip pain. This revealed edema in the right ilium at the posterosuperior aspect of the acetabulum. He was switched to tocilizumab infusion $8 \mathrm{mg} / \mathrm{kg}$ (600 mg) every 2 weeks due to persistent infliximab-associated psoriasis. However, his uveitis flared in June 2013 and required a second subtenon injection in his right eye. In July 2013, tocilizumab was switched back to infliximab at $6 \mathrm{mg} / \mathrm{kg}$ (500 mg) every 4 weeks due to inadequate control of uveitis and arthritis.

In July 2013, pelvis MRI was repeated and revealed increased bone edema in acetabulum and new edema in proximal femurs consistent with chronic recurrent multifocal osteomyelitis (CRMO) (Figure 3). Due to the 

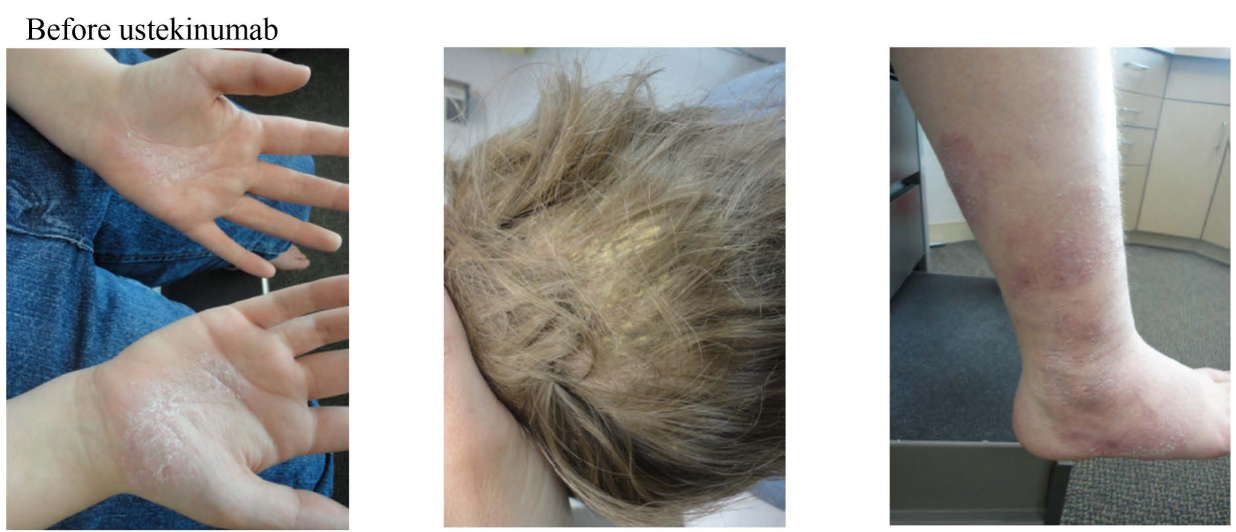

Six months after starting ustekinumab
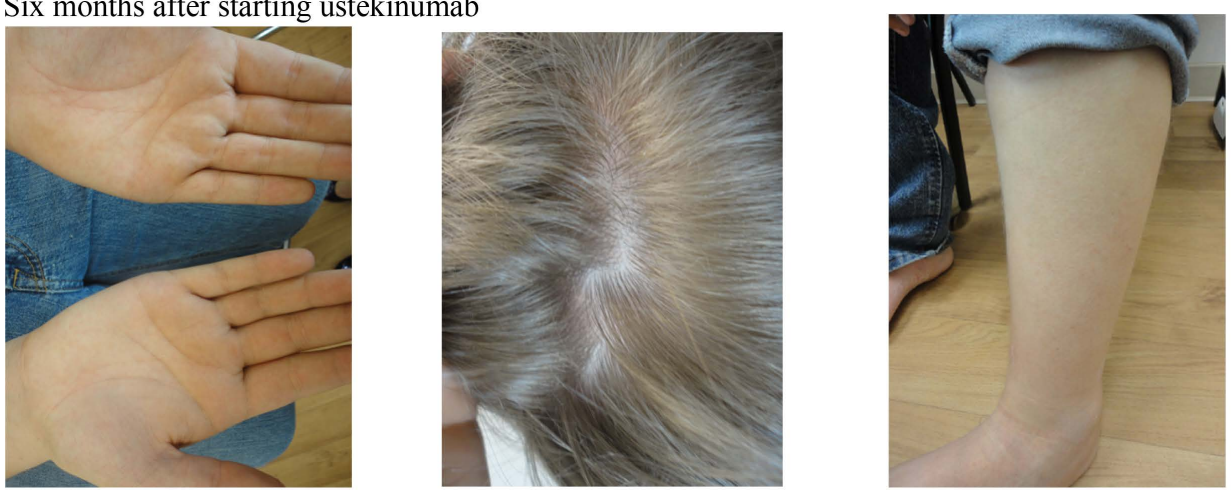

Figure 2. Psoriatic skin lesions in scalp, palms and lower extremities are shows on the top panel prior to starting ustekinumab. Near complete resolution of psoriatic lesions 6 months after starting ustekinumab are shown on the bottom panel.

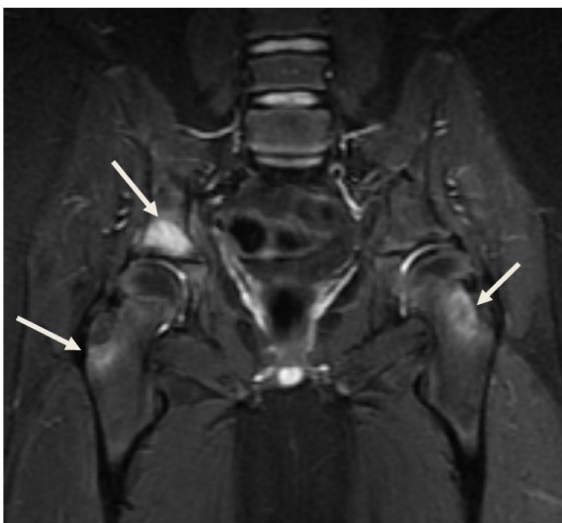

STIR coronal $7 / 24 / 2013$

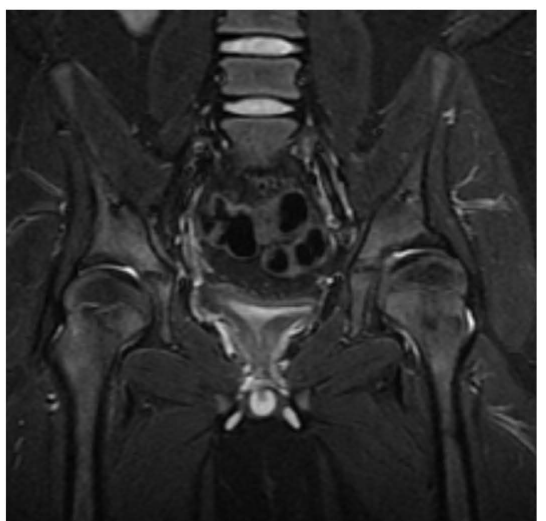

STIR coronal 12/12/2013

Figure 3. Coronal short tau inversion recovery (STIR) sequence of pelvic MRI in July 2013 (left panel) and December 2013 (right panel) are shown. Arrows indicate active bone inflammation with hyperintense signals.

classic chronic course, multifocal bone lesions, and associated psoriasis, it was felt that bone biopsy was not needed. In September 2013, his Infliximab dose was increased from $6 \mathrm{mg} / \mathrm{kg}$ to $10 \mathrm{mg} / \mathrm{kg}$ every 4 weeks. He received one dose of $70 \mathrm{mg}(1 \mathrm{mg} / \mathrm{kg})$ pamidronate for his CRMO and had severe reactions including dysuria and headache. He has been consistently given infliximab every $4-6$ weeks at $10 \mathrm{mg} / \mathrm{kg}(800 \mathrm{mg})$ since October 2013. Whole-body MRI was not available so a repeat MRI of pelvis was obtained in December 2013 and showed resolution of previously seen bone edema (Figure 3). 
An attempt to resolve the psoriasis was made by decreasing frequency and dosing of infliximab between March and September 2014 but did not help. Additionally, he had a mild flare of uveitis during this period which resolved quickly with short courses of difluprednate eye drops. His palmar, plantar psoriasis and scalp psoriasis persisted. In June 2014, ustekinumab $45 \mathrm{mg}$ was initiated and has continued every 3 months. Four months later his skin had cleared by greater than $50 \%$. Six months after starting ustekinumab, his skin lesions were $90 \%$ clear (Figure 2).

He had another uveitis flare in September 2014. His infliximab dose was increased to $12.5 \mathrm{mg} / \mathrm{kg}$ (1000 mg) for 2 doses and his difluprednate eye drop was restarted at 1 drop twice daily for 3 weeks, which quickly resolved his uveitis. His infliximab dose was decreased back to $10 \mathrm{mg} / \mathrm{kg}$ ( $800 \mathrm{mg}$ ) every 4 weeks since November 2014. Another follow-up MRI of pelvis was done in December 2014 and showed no recurrence of bone inflammation.

He did not follow up with an ophthalmologist until April 2015 when he was found to have 1+ cell in right eye. Difluprednate eye drop was restarted at 1 drop twice daily while keeping infliximab at $800 \mathrm{mg}$ every 4 weeks. In September 2015, he had eye pain and photosensitivity in his right eye and self-initiated difluprednate1 drop twice daily until he saw ophthalmologist at the end of September 2015. At that exam, there were 1 - 2+ cells in his right anterior chamber. His posterior subcapsular cataract is mild and stable. Visual acuity corrects to 20/20.

In summary, his uveitis, arthritis and CRMO have been reasonably controlled by infliximab and his psoriasis almost resolved with the addition of ustekinumab.

\section{Discussion}

This case highlights the importance of imaging studies to detect CRMO. Our patient has features of Enthesitis-related arthritis (HLA-B27 positive, acute iritis, arthritis in a male older than 6) which has been reported to associate with CRMO [23]. In our patient, persistent pain raised concern of another associated condition, CRMO. MRI was useful to identify the active bone inflammation despite a normal joint exam. Comparing to other imaging modalities, such as bone scan and $\mathrm{x}$ ray, MRI is more sensitive in detecting bone lesions for CRMO [7] [9] and MRI remains an important disease-monitoring tool for CRMO [24] [25].

The treatment of CRMO comprises of a variety of medications including nonsteroidal anti-inflammatory drugs (NSAIDs), methotrexate, sulfasalazine, anti-TNF agents and bisphosphonate [4] [24]-[27]. In a recent report, combination of methotrexate and infliximab with or without bisphosphonate has shown significantly decreased pain, inflammation marker and severity of bone edema in CRMO [25]. In our patient, a single dose of pamidronate and increasing dose of infliximab induced near resolution of bone inflammation 5 months later as confirmed by repeated MRI. His CRMO remained inactive with infliximab at $10 \mathrm{mg} / \mathrm{kg}$ every 4 - 6 weeks.

Psoriasis can be associated with CRMO as well as induced by TNF alpha inhibitors [17]-[21]. His psoriasis occurred after the initiation of monoclonal anti-TNF agents, infliximab and adalimumab. The timing of development of his psoriasis implied a role of anti-TNF agent to induce psoriasis. Anti-TNF agents have been associated with psoriasis in adults and children [17] [19] [28]. The mechanism is unclear but recent study in pediatric Crohn's disease population suggested a link of higher risk of anti-TNF associated psoriasis with homozygous polymorphism of IL23 receptor [28]. Unfortunately, infliximab was the most effective biologic for our patient's uveitis, which posed a practical challenge to the care of hispsoriasis. His psoriasis failed to respond to topical glucocorticoids (partly due to poor compliance). IL 23 is essential in the development of Th 17 lymphocytes [29] which is an important pathway driving the disease process in psoriasis. Ustekinumb, an IL12/23 blocker, has been shown effective in treating psoriasis for adults and approved by FDA [30]. It was reported as effective in children in a recent randomized clinical trial [31].

The combination of ustekinumab and anti-TNF agents has been used for refractory psoriasis in adult patients with psoriatic arthritis [32]. Based on 16.2 patient-years observation, psoriasis area severity index (PASI) decreased from between 11.2 and 30 to between 1.2 and 3 after adding ustekinumab to anti-TNF agent. Among 4 patients, one developed relapsing herpes zoster, one developed a skin infection both resolved after standard antibiotic treatments. Another patient developed a retrotonsillar abscess which resolved after incision and intravenous antibiotics.

Indeed, our patient responded to ustekinumab added to infliximab within 4 months with $50 \%$ clearance and further improvement of $90 \%$ clearance after 6 months of treatment. Combining two biologic treatments may potentially increase the risk of infection. Our patient has not had any infections for the 15 months of observation 
while receiving a combination of anti-TNF alpha and anti-IL 12/23 agents. In an animal model for rheumatoid arthritis, bispecific antibody that blocks both TNF alpha and IL-17 improved joint inflammation more than any single blockade of these two cytokines [33] [34]. Thus, combining anti-TNF alpha and anti-IL 17 may provide a treatment option for complicated patient like ours with refractory uveitis, chronic arthritis, chronic osteomyelitis and severe psoriasis.

\section{Conclusion}

MRI should be considered to evaluate unexplained bone pain in children with JIA as chronic recurrent multifocal osteomyelitis can occur. When TNF alpha inhibitor-associated psoriasis fails to respond to topical therapy, combining ustekinumab with TNF alpha inhibitor may be considered when risks are assessed fully.

\section{Acknowledgements}

We wish to thank the patient and his family for participation in the study. We also thank Dr. Ronald Laxer for his constructive suggestions on this manuscript and Heather Marshall, RN, for her excellent assistance in obtaining past medical records.

\section{Consent}

This report was developed with approval by the institutional review board of Seattle Children's Hospital, Seattle and written informed consent was obtained from the patient's parents. Assent was obtained from the patient.

\section{Competing Interests}

The authors declare that they have no competing interest.

\section{Authors' Contributions}

YZ, SF, TM, MS, CAW collected and interpreted clinical findings. YZ, SF and CAW wrote the manuscript. All authors read and approved the final manuscript.

\section{References}

[1] Jansson, A.F. and Grote, V. (2011) Nonbacterial Osteitis in Children: Data of a German Incidence Surveillance Study. Acta Paediatrica, 100, 1150-1157. http://dx.doi.org/10.1111/j.1651-2227.2011.02205.x

[2] Beretta-Piccoli, B.C., et al. (2000) (SAPHO) Syndrome in Childhood: A Report of Ten Cases and Review of the Literature. European Journal of Pediatrics, 159, 594-601. http://dx.doi.org/10.1007/s004310000500

[3] McGonagle, D. and Emery, P. (2000) Enthesitis, Osteitis, Microbes, Biomechanics, and Immune Reactivity in Ankylosing Spondylitis. Journal of Rheumatology, 27, 2302-2304.

[4] Borzutzky, A., et al. (2012) Pediatric Chronic Nonbacterial Osteomyelitis. Pediatrics, 130, e1190-e1197. http://dx.doi.org/10.1542/peds.2011-3788

[5] Girschick, H.J., et al. (2005) Chronic Non-Bacterial Osteomyelitis in Children. Annals of the Rheumatic Diseases, 64, 279-285. http://dx.doi.org/10.1136/ard.2004.023838

[6] Bousvaros, A., et al. (1999) Chronic Recurrent Multifocal Osteomyelitis Associated with Chronic Inflammatory Bowel Disease in Children. Digestive Diseases and Sciences, 44, 2500-2507. http://dx.doi.org/10.1023/A:1026695224019

[7] Fritz, J., Claussen, C.D., Carrino, J.A. and Horger, M.S. (2009) Chronic Recurrent Multifocal Osteomyelitis: Comparison of Whole-Body MR Imaging with Radiography and Correlation with Clinical and Laboratory Data. Radiology, 252, 842-851. http://dx.doi.org/10.1148/radiol.2523081335

[8] Hobolth, L., Nemery, M., Albrectsen, J. and Hasbak, P. (2008) Chronic Recurrent Multifocal Osteomyelitis Demonstrated by Tc-99m Methylene Diphosphonate Bone Scan. Clinical Nuclear Medicine, 33, 61-63. http://dx.doi.org/10.1097/RLU.0b013e31815c5035

[9] Morbach, H., et al. (2012) Comparison of Magnetic Resonance Imaging and Technetium-Labelled Methylene Diphosphonate Bone Scintigraphy in the Initial Assessment of Chronic Non-Bacterial Osteomyelitis of Childhood and Adolescents. Clinical and Experimental Rheumatology, 30, 578-582. http://dx.doi.org/10.1016/j.ophtha.2009.05.002

[10] Smith, J.A., et al. (2009) Epidemiology and Course of Disease in Childhood Uveitis. Ophthalmology, 116, $1544-1551$. 
[11] Holland, G.N., Denove, C.S. and Yu, F. (2009) Chronic Anterior Uveitis in Children: Clinical Characteristics and Complications. American Journal of Ophthalmology, 147, 667-678. http://dx.doi.org/10.1016/j.ajo.2008.11.009

[12] Liao, C.-H. and Huang, J.-L. (2003) Juvenile Ankylosing Spondylitis with Uveitis. Asian Pacific Journal of Allergy and Immunology, 21, 69-71.

[13] Rajaraman, R.T., Kimura, Y., Li, S., Haines, K. and Chu, D.S. (2006) Retrospective Case Review of Pediatric Patients with Uveitis Treated with Infliximab. Ophthalmology, 113, 308-314. http://dx.doi.org/10.1016/j.ophtha.2005.09.037

[14] Kahn, P., Weiss, M., Imundo, L.F. and Levy, D.M. (2006) Favorable Response to High-Dose Infliximab for Refractory childhood Uveitis. Ophthalmology, 113, 860-864. http://dx.doi.org/10.1016/j.ophtha.2006.01.005

[15] Gallagher, M., Quinones, K., Cervantes-Castañeda, R.A., Yilmaz, T. and Foster, C.S. (2007) Biological Response Modifier Therapy for Refractory Childhood Uveitis. British Journal of Ophthalmology, 91, 1341-1344. http://dx.doi.org/10.1136/bjo.2007.124081

[16] Biester, S., et al. (2007) Adalimumab in the Therapy of Uveitis in Childhood. British Journal of Ophthalmology, 91, 319-324. http://dx.doi.org/10.1136/bjo.2006.103721

[17] Shale, M. and Ghosh, S. (2009) Learning the Lessons of Antitumour Necrosis Factor Therapy-Associated Psoriasis. The Canadian Journal of Gastroenterology, 23, 674-676. http://dx.doi.org/10.1155/2009/514618

[18] Cohen, J.D., et al. (2007) Psoriasis Induced by Tumor Necrosis Factor-Alpha Antagonist Therapy: A Case Series. The Journal of Rheumatology, 34, 380-385.

[19] Wollina, U., et al. (2008) Tumor Necrosis Factor-Alpha Inhibitor-Induced Psoriasis or Psoriasiform Exanthemata: First 120 Cases from the Literature Including a Series of Six New Patients. American Journal of Clinical Dermatology, 9, 114. http://dx.doi.org/10.2165/00128071-200809010-00001

[20] Shmidt, E., Wetter, D.A., Ferguson, S.B. and Pittelkow, M.R. (2012) Psoriasis and Palmoplantar Pustulosis Associated with Tumor Necrosis Factor- $\alpha$ Inhibitors: The Mayo Clinic Experience, 1998 to 2010. Journal of the American Academy of Dermatology, 67, e179-e185. http://dx.doi.org/10.1016/j.jaad.2011.05.038

[21] Collamer, A.N., Guerrero, K.T., Henning, J.S. and Battafarano, D.F. (2008) Psoriatic Skin Lesions Induced by Tumor Necrosis Factor Antagonist Therapy: A Literature Review and Potential Mechanisms of Action. Arthritis \& Rheumatology, 59, 996-1001. http://dx.doi.org/10.1002/art.23835

[22] Petty, R.E., et al. (2004) International League of Associations for Rheumatology Classification of Juvenile Idiopathic Arthritis: Second Revision, Edmonton, 2001. The Journal of Rheumatology, 31, 390-392.

[23] Vittecoq, O., et al. (2000) Evolution of Chronic Recurrent Multifocal Osteitis toward Spondylarthropathy over the Long Term. Arthritis \& Rheumatology, 43, 109-119. http://dx.doi.org/10.1002/1529-0131(200001)43:1<109::AID-ANR14>3.0.CO;2-3

[24] Beck, C., et al. (2010) Chronic Nonbacterial Osteomyelitis in Childhood: Prospective Follow-Up during the First Year of Anti-Inflammatory Treatment. Arthritis Research \& Therapy, 12, R74. http://dx.doi.org/10.1186/ar2992

[25] Zhao, Y., Chauvin, N.A., Jaramillo, D. and Burnham, J.M. (2015) Aggressive Therapy Reduces Disease Activity without Skeletal Damage Progression in Chronic Nonbacterial Osteomyelitis. The Journal of Rheumatology, 42, 12451251. http://dx.doi.org/10.3899/jrheum.141138

[26] Hospach, T., Langendoerfer, M., von Kalle, T., Maier, J. and Dannecker, G.E. (2010) Spinal Involvement in Chronic Recurrent Multifocal Osteomyelitis (CRMO) in Childhood and Effect of Pamidronate. European Journal of Pediatrics, 169, 1105-1111. http://dx.doi.org/10.1007/s00431-010-1188-5

[27] Job-Deslandre, C., Krebs, S. and Kahan, A. (2001) Chronic Recurrent Multifocal Osteomyelitis: Five-Year Outcomes in 14 Pediatric Cases. Joint Bone Spine, 68, 245-251. http://dx.doi.org/10.1016/S1297-319X(01)00276-7

[28] Sherlock, M.E., et al. (2013) Infliximab-Induced Psoriasis and Psoriasiform Skin Lesions in Pediatric Crohn Disease and a Potential Association with IL-23 Receptor Polymorphisms. Journal of Pediatric Gastroenterology and Nutrition, 56, 512-518. http://dx.doi.org/10.1097/MPG.0b013e31828390ba

[29] Toussirot, E. (2012) The IL23/Th17 Pathway as a Therapeutic Target in Chronic Inflammatory Diseases. Inflammation \& Allergy-Drug Targets, 11, 159-168. http://dx.doi.org/10.2174/187152812800392805

[30] Papp, K.A., et al. (2008) Efficacy and Safety of Ustekinumab, a Human Interleukin-12/23 Monoclonal Antibody, in Patients with Psoriasis: 52-Week Results from a Randomised, Double-Blind, Placebo-Controlled Trial (PHOENIX 2). Lancet, 371, 1675-1684. http://dx.doi.org/10.1016/S0140-6736(08)60726-6

[31] Landells, I., et al. (2015) Ustekinumab in Adolescent Patients Age 12 to 17 Years with Moderate-to-Severe Plaque Psoriasis: Results of the Randomized Phase 3 CADMUS Study. Journal of the American Academy of Dermatology, 73, 594-603. http://dx.doi.org/10.1016/j.jaad.2015.07.002

[32] Gniadecki, R., Bang, B. and Sand, C. (2016) Combination of Antitumour Necrosis Factor- $\alpha$ and Anti-Interleukin-12/23 Antibodies in Refractory Psoriasis and Psoriatic Arthritis: A Long-Term Case-Series Observational Study. British 
Journal of Dermatology, 174, 1145-1146.

[33] Fischer, J.A.A., et al. (2015) Combined Inhibition of Tumor Necrosis Factor $\alpha$ and Interleukin-17 as a Therapeutic Opportunity in Rheumatoid Arthritis: Development and Characterization of a Novel Bispecific Antibody. Arthritis \& Rheumatology (Hoboken, NJ), 67, 51-62. http://dx.doi.org/10.1002/art.38896

[34] Buckland, J. (2014) Rheumatoid Arthritis: Anti-TNF and Anti-IL-17 Antibodies-Better Together! Nature Reviews Rheumatology, 10, 699-699. http://dx.doi.org/10.1038/nrrheum.2014.183

\section{Abbreviations}

JIA, IBD, anti-TNF, CRMO, MRI.

Submit or recommend next manuscript to SCIRP and we will provide best service for you:

Accepting pre-submission inquiries through Email, Facebook, Linkedin, Twitter, etc A wide selection of journals (inclusive of 9 subjects, more than 200 journals)

Providing a 24-hour high-quality service

User-friendly online submission system

Fair and swift peer-review system

Efficient typesetting and proofreading procedure

Display of the result of downloads and visits, as well as the number of cited articles

Maximum dissemination of your research work

Submit your manuscript at: http://papersubmission.scirp.org/ 